\title{
Preparation, Structure and Physical Properties of BEDT-TTF* Nitrates
}

\author{
A. Weber, H. Endres, and H. J. Keller ${ }^{+}$
}

Anorganisch-Chemisches Institut der Universität Heidelberg, Im Neuenheimer Feld 270, D-6900 Heidelberg 1, FRG

E. Gogu, I. Heinen, K. Bender, and D. Schweitzer

Abt. für Molekulare Physik, Max-Planck-Institut für Medizinische Forschung, Jahnstraße 29, D-6900 Heidelberg 1, FRG

Z. Naturforsch. 40 b, 1658-1663 (1985); received July 30, 1985

Structure, Radical Ion Salts, Organic Conductors

Electrocrystallization of BEDT-TTF in THF with tetrabutylammonium nitrate as supporting electrolyte leads to the deposition of at least three different phases.

The $\alpha$-phase $\left(\mathrm{C}_{10} \mathrm{H}_{8} \mathrm{~S}_{8}\right)_{3}\left(\mathrm{NO}_{3}\right)_{2}, \mathrm{M}_{\mathrm{r}}=1277.98$, crystallizes in the monoclinic space group $\mathrm{P} 2_{1} / n$. The structure of this solid was solved: $a=5.890(2), b=31.125(10), c=12.915(6) \AA$, $\beta=103.73(3)^{\circ}, \mathrm{V}=2300 \AA^{3}, Z=2, \mathrm{D}_{x}=1.84 \mathrm{~g} \mathrm{~cm}^{-3}, \mathrm{MoK}_{\alpha}, \lambda=0.7107 \AA, \mu=11.2 \mathrm{~cm}^{-1}$, $\mathrm{F}(000)=1300$, room temperature, $R=0.057$ for 1888 observed independent reflections. Sheets of BEDT-TTF radical cations with short intermolecular S $\cdots$ S contacts $(>3.315(4) \AA)$ are separated by anion layers. Two more BEDT-TTF nitrates have been characterized by their unit cell data. Results of temperature dependent electrical conductivity and thermopower measurements on crystals of the $a$-phase are presented. They are metallic down to about $30 \mathrm{~K}$.

\section{Introduction}

At this time BEDT-TTF is the most promising donor in the search for new metallic or even superconducting radical ion salts. The first report of a superconducting phase containing (BEDT-TTF) ${ }^{+}$cations was concerned with the $\mathrm{ReO}_{4}^{-}$salt [1]. Later on superconducting phases of BEDT-TTF have been obtained mainly with linear triatomic counter anions like different trihalides (e.g. $\mathrm{I}_{3}{ }^{-}$, or $\left.\mathrm{BrI}_{2}{ }^{-}\right)$and $\left(\mathrm{AuI}_{2}\right)^{-}[2-8]$. There is a problem connected with the electrocrystallization of the trihalide compounds. The primary reaction is the oxidation of the iodine containing trihalides leading to rearrangement $-e . g$. symmetrization - reactions in the counter ions [9]. We, therefore, used tetrabutylammonium nitrate as a supporting electrolyte and report in the following the structure and properties of the products obtained during the electrochemical oxidation of BEDT-TTF in the presence of $\mathrm{NO}_{3}{ }^{-}$as counterions.

\section{Experimental}

\section{Preparation}

Tetrabutylammonium nitrate was purchased from Fluka and recrystallized several times from small amounts of benzene. BEDT-TTF was obtained as

- BEDT-TTF $=\mathrm{C}_{10} \mathrm{H}_{8} \mathrm{~S}_{8}=\operatorname{Bis}(1,2$-ethylenedithiolo)tetrathiafulvalene.

+ Reprint requests to Prof. Dr. H. J. Keller.

Verlag der Zeitschrift für Naturforschung, D-7400 Tübingen 0340-5087/85/1200-1658/\$ 01.00/0 described earlier $[10,11]$. The electrolyte solution in THF was saturated at about $60-70^{\circ} \mathrm{C}$ with the donor BEDT-TTF and electrolyzed in an arrangement described earlier [12, 13]. Galvanostatic as well as potentiostatic electrolyses $(\sim 1.8 \mathrm{~V} ; 5-15 \mu \mathrm{A})$ were carried out.

As apparent from microscopic investigations, different types of crystals are obtained by these electrocrystallizations. Nevertheless, quite consistent values of the elemental analysis result if different badges of the products are analyzed.

Typical observed values for different mixtures of the crystals were:

$$
\begin{aligned}
& \text { C: } 27.98 \%-28.86 \% ; \mathrm{H}: \quad 1.56 \%-1.86 \% \text {; } \\
& \mathrm{N}: 2.00 \%-2.12 \% \text {; }: 60.65 \%-63.28 \% \text {. }
\end{aligned}
$$

Calculated for (BEDT-TTF) $)_{3}\left(\mathrm{NO}_{3}\right)_{2}, \mathrm{C}_{30} \mathrm{H}_{24} \mathrm{~S}_{24} \mathrm{~N}_{2} \mathrm{O}_{6}$ :

$$
\text { C: } 28.19 \% \text {; H: } 1.89 \% \text {; N: } 2.19 \% \text {; S: } 60.20 \% \text {. }
$$

This result points to the fact that different modifications of the same stoichiometry are isolated.

Single crystal Weissenberg and diffractometer investigations revealed the occurrence of three phases.

Besides the $a$-phase described in detail below, two more monoclinic phases have been identified:

\section{$\beta$-phase:}

$a=6.529(1) \AA, b=12.379(4) \AA, c=$ $28.487(11) \AA, \beta=95.01(3)^{\circ}, V=2294 \AA^{3}$; space group $\mathrm{P} 21 / c$.

$\gamma$-phase:

$a=15.035(6) \AA, b=6.584(2) \AA, c=$ $30.900(15) \AA, \beta=101.64(4)^{\circ}, V=2996 \AA^{3}$; space group $\mathrm{P} 21 / n$. 
This paper is concerned with the investigation of the $\alpha$-phase only.

\section{Physical investigations}

The electrical conductivity of the nitrate phases was measured by the standard four probe method with $\mathrm{dc}$ and a low frequency $(4-10 \mathrm{~Hz})$ lock-intechnique in the temperature range between 1.3 and $300 \mathrm{~K}$. Gold leads $(0.015 \mathrm{~mm}$ diameter $)$ were attached to the samples with silver or gold paint on previously deposited gold pads, yielding contact resistencies of a few ohms. Both dc and ac methods gave identical results.

Thermopower measurements were performed in the temperature range between 10 and $300 \mathrm{~K}$ with a device similar to that described in the literature [14].

\section{$X$-ray investigation of the $\alpha$-phase}

A black elongated plate, $0.28 \times 0.1 \times$ $0.015 \mathrm{~mm}^{3}$ was mounted on top of a glass capillary. Lattice parameters were derived from the setting angles of 25 reflections (Syntex R3 diffractometer, monochromated $\mathrm{MoK}_{a}$ radiation). Data collection by $\theta-2 \theta$ scans background-peak-background, $2 \theta<50^{\circ}$, yielded 1888 observed independent reflections with I $>2.5 \sigma(\mathrm{I})$. An empirical absorption correction using $\psi$-scans of five reflections with $10.6^{\circ}<2 \theta<35.6^{\circ}$ was applied.

The structure was solved by direct methods and Fourier syntheses. The methylene groups were refined as rigid groups with calculated $\mathbf{H}$ positions. Non-H atoms were refined with anisotropic temperature factors ( 280 parameters) by cascade matrix least squares based on $\mathrm{F}$, with weights $w=1 / \sigma^{2}(\mathrm{~F})$. Refinement converged with $R_{\mathrm{w}}(R)=0.049(0.057)$, a goodness of fit of 1.59 and max. shift/error of 0.05 . The largest features in a final difference Fourier map were +0.47 and $-0.43 \mathrm{e} \AA^{-3}$.
Calculations were performed with the SHELXTL program package [15] on a Nova 3 computer using scattering factors, including anomalous dispersion, from International Tables for X-ray Crystallography [16]. Plots were done on a Tektronix plotter with SHELXTL.

\section{Discussion}

\section{Structure}

Atom coordinates are listed in Table $\mathrm{I}^{*}$. Fig. 1 shows the numbering scheme in the two crystallographically different BEDT-TTF species, bond distances and angles are listed in Table II. Species (I), $\mathrm{S}(1)-\mathrm{C}(10)$, lies on a general position, species (II), $\mathrm{S}(9)-\mathrm{C}(15)$, on a crystallographic inversion center, and the nitrate ion on a general position. The BEDT-TTF moieties are arranged side by side to form a ribbon extending along the direction $(-2,0,1$ (Fig. 2)), were two species (I) alternate with one species (II). Pronounced intermolecular $\mathrm{S} \cdots \mathrm{S}$ interactions occur, with distances as short as 3.315(5) $\AA$. These range within the shortest ones ever observed in BEDT-TTF salts and are important for the physical properties. Other prominent S...S contacts are formed between the molecules of adjacent ribbons related by a unit translation $a$ (Fig. 3). These intra- and inter-ribbon interactions result in the formation of sheets of BEDT-TTF and lead to

\footnotetext{
* Lists of structure amplitudes, anisotropic thermal parameters, and further details of the $\mathrm{X}$-ray investigations have been deposited with the Fachinformationszentrum Energie, Physik, Mathematik, D-7514 EggensteinLeopoldshafen 2, FRG. Copies may be obtained quoting the deposition number CSD 51600, the authors, and the journal reference.
}

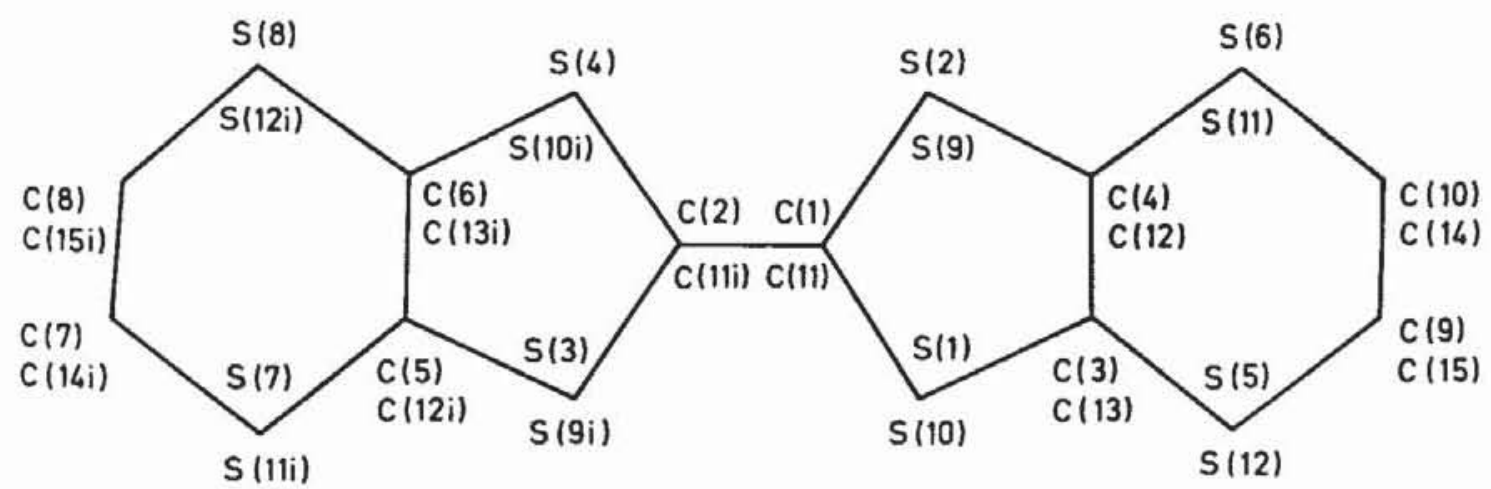

Fig. 1. Numbering scheme in the two crystallographically different BEDT-TTF moieties. Upper numbers refer to molecule (I), lower ones to molecule (II). Symmetry code i: $-x,-y, 2-z$. 
Table I. Atom coordinates $\left(\times 10^{4}\right)$ and isotropic temperature factors $\left(\AA^{2} \times 10^{3}\right)$ equivalent to the refined anisotropic values and defined as $1 / 3$ of the trace of the orthogonalized $\mathrm{U}_{\mathrm{ij}}$ tensor.

\begin{tabular}{|c|c|c|c|c|}
\hline Atom & $x$ & $y$ & $z$ & $\mathbf{U}$ \\
\hline$S(1)$ & $1973(4)$ & $-200(1)$ & $4086(2)$ & $45(1)$ \\
\hline$S(2)$ & $5108(4)$ & $-113(1)$ & $2650(2)$ & $45(1)$ \\
\hline$S(3)$ & $-93(4)$ & $741(1)$ & $3445(2)$ & $41(1)$ \\
\hline S(4) & $3268(4)$ & $872(1)$ & $2134(2)$ & $42(1)$ \\
\hline$S(5)$ & $3594(5)$ & $-1062(1)$ & $4854(2)$ & $56(1)$ \\
\hline$S(6)$ & $7282(4)$ & $-962(1)$ & $3118(2)$ & $55(1)$ \\
\hline$S(7)$ & $-1805(4)$ & $1630(1)$ & $3318(2)$ & $46(1)$ \\
\hline S(8) & $2238(4)$ & $1793(1)$ & $1742(2)$ & $53(1)$ \\
\hline$C(1)$ & $2977(14)$ & $122(3)$ & $3193(7)$ & $34(4)$ \\
\hline$C(2)$ & 2151(14) & $526(3)$ & $2940(6)$ & $32(3)$ \\
\hline$C(3)$ & $3844(14)$ & $-637(3)$ & $4041(7)$ & $35(3)$ \\
\hline$C(4)$ & $5292(13)$ & $-586(3)$ & $3368(6)$ & $31(3)$ \\
\hline$C(5)$ & $63(13)$ & $1261(3)$ & $2957(6)$ & $33(3)$ \\
\hline C(6) & $1656(13)$ & 1321(3) & $2344(7)$ & $34(3)$ \\
\hline$C(7)$ & $-1208(21)$ & $2106(3)$ & $2677(10)$ & $106(7)$ \\
\hline$C(8)$ & $572(25)$ & $2152(3)$ & $2236(12)$ & $148(10)$ \\
\hline C(9) & $5087(19)$ & $-1469(3)$ & $4338(11)$ & $92(7)$ \\
\hline$C(10)$ & $6958(24)$ & $-1397(4)$ & $3920(10)$ & $114(8)$ \\
\hline$S(9)$ & $-2502(4)$ & $450(1)$ & $10407(2)$ & $39(1)$ \\
\hline$S(10)$ & $814(4)$ & 534(1) & $9056(2)$ & $43(1)$ \\
\hline$S(11)$ & $-4258(4)$ & 1332(1) & $10110(2)$ & 47(1) \\
\hline$S(12)$ & $-363(4)$ & $1434(1)$ & $8442(2)$ & $46(1)$ \\
\hline$C(11)$ & - 334(14) & $203(2)$ & $9894(7)$ & $33(3)$ \\
\hline$C(12)$ & $-2354(13)$ & $947(3)$ & $9810(6)$ & $31(3)$ \\
\hline$C(13)$ & $-848(13)$ & $990(3)$ & $9181(7)$ & $33(3)$ \\
\hline$C(14)$ & $-4240(14)$ & $1734(3)$ & $9110(7)$ & $43(4)$ \\
\hline C(15) & $-1789(14)$ & $1854(3)$ & $8995(7)$ & $43(4)$ \\
\hline$N(1)$ & $9327(16)$ & $2301(3)$ & $5702(8)$ & $55(4)$ \\
\hline$O(1)$ & 9372(13) & $2151(2)$ & $6588(7)$ & $80(4)$ \\
\hline$O(2)$ & $11173(12)$ & $2333(2)$ & $5369(6)$ & $70(3)$ \\
\hline$O(3)$ & $7483(13)$ & $2428(3)$ & $5094(7)$ & $82(4)$ \\
\hline
\end{tabular}

the two-dimensional physical behaviour of the compound. Alternatively, the occurrence of stacks of BEDT-TTF may be recognized in Fig. 3, but there are no intermolecular S $\cdots$ S contacts $<4 \AA$ within a stack.

Along $b$, the sheets of BEDT-TTF cations are separated from each other by layers of $\mathrm{NO}_{3}{ }^{-}$anions. It could be deduced from composition and symmetry that BEDT-TTF species (I) carries the positive charge, and species (II) is a neutral molecule. This is, however, not consistent with the physical behaviour, which makes the occurrence of cations with fractional average charge more likely.

\section{Physical results}

The electrical conductivity was measured along the $a$-axes of crystals of $a$-(BEDT-TTF $)_{3}\left(\mathrm{NO}_{3}\right)_{2}$. The room temperature conductivity ranges typically between 100 and $800(\Omega \mathrm{cm})^{-1}$ (Figs. 4 and 5).

The conductivity data of several samples indicate a phase transition around $20 \mathrm{~K}$ (see Fig. 4). Other crystals do not show such a sharp decrease in the conductivity at this temperature (see Fig. 5). Figs. 4 and 5 show two extreme cases of many measurements. Most of the crystals show a temperature dependence intermediate between these two extremes. Nevertheless all crystals have in common a metallic behaviour down to about $30 \mathrm{~K}$, while below $20 \mathrm{~K}$ the conductivity decreases only slightly indicating a semi-

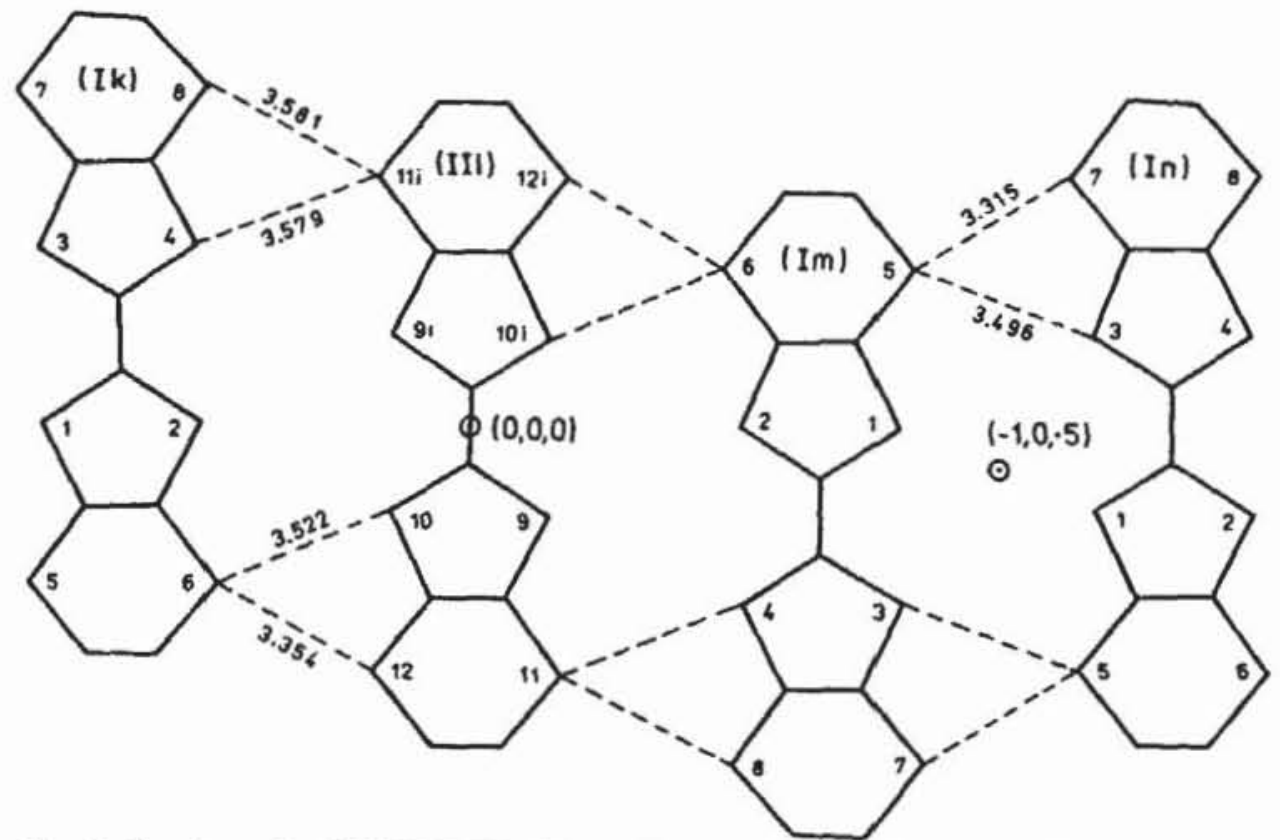

Fig. 2. Section of a BEDT-TTF ribbon showing intermolecular S $\cdots$ S contacts $<3.8 \AA$ (e.s.d. $\sim 0.005 \AA$ ). Circled dots indicate crystallographic inversion centers with the given coordinates. Numbered atoms are the $\mathrm{S}$ atoms, (I) and (II) designate the two BEDT-TTF species. Symmetry codes are $\mathrm{k}: 1-x,-y,-z ; 1: x, y, z-1 ; \mathrm{m}: x-1, y, z ; \mathrm{n}:-1-x,-y, 1-z$. The molecular centroids are at: (Ik): .74, $-.03,-.31$; (III): $0,0,0$; (Im): $-.74, .03, .31$; (In): $-1.26,-.03, .69$. 


\begin{tabular}{|c|c|c|c|}
\hline$S(1)-C(1)$ & $1.734(9)$ & $S(1)-C(3)$ & $1.760(9)$ \\
\hline$S(2)-C(1)$ & $1.738(9)$ & $S(2)-C(4)$ & $1.731(8)$ \\
\hline$S(3)-C(2)$ & $1.740(9)$ & $\mathrm{S}(3)-\mathrm{C}(5)$ & $1.748(9)$ \\
\hline$S(4)-C(2)$ & $1.733(9)$ & $S(4)-C(6)$ & $1.746(9)$ \\
\hline$S(5)-C(3)$ & $1.717(9)$ & $S(5)-C(9)$ & $1.762(12)$ \\
\hline$s(6)-C(4)$ & $1.739(9)$ & $S(6)-C(10)$ & $1.745(13)$ \\
\hline$S(7)-C(5)$ & $1.729(9)$ & $S(7)-C(7)$ & $1.773(12)$ \\
\hline$S(8)-C(6)$ & $1.732(9)$ & $\mathrm{S}(8)-\mathrm{C}(8)$ & $1.707(15)$ \\
\hline$C(1)-C(2)$ & $1.358(12)$ & $C(3)-C(4)$ & $1.364(13)$ \\
\hline$C(5)-C(6)$ & $1.376(13)$ & $C(7)-C(8)$ & $1.315(22)$ \\
\hline $\mathrm{C}(9)-\mathrm{C}(10)$ & $1.356(20)$ & $S(9)-C(11)$ & $1.749(9)$ \\
\hline$S(9)-C(12)$ & $1.739(8)$ & $S(10)-C(11)$ & $1.743(9)$ \\
\hline$S(10)-C(13)$ & $1.753(9)$ & $\mathrm{S}(11)-\mathrm{C}(12)$ & $1.747(9)$ \\
\hline$S(11)-C(14)$ & $1.800(9)$ & $S(12)-C(13)$ & $1.742(9)$ \\
\hline$S(12)-C(15)$ & $1.793(9)$ & $C(11)-C(11 a)$ & $1.332(15)$ \\
\hline$C(12)-C(13)$ & $1.344(12)$ & $C(14)-C(15)$ & $1.533(12)$ \\
\hline$N(1)-O(1)$ & $1.230(13)$ & $\mathrm{N}(1)-\mathrm{O}(2)$ & $1.264(13)$ \\
\hline $\mathrm{N}(1)-\mathrm{O}(3)$ & $1.245(11)$ & & \\
\hline$C(1)-S(1)-C(3)$ & $96.3(4)$ & $C(1)-S(2)-C(4)$ & $95.8(4)$ \\
\hline$C(2)-S(3)-C(5)$ & $96.4(4)$ & $C(2)-S(4)-C(6)$ & $96.1(4)$ \\
\hline$C(3)-S(5)-C(9)$ & $101.6(5)$ & $C(4)-S(6)-C(10)$ & $103.8(6)$ \\
\hline$C(5)-S(7)-C(7)$ & $102.6(5)$ & $C(6)-S(8)-C(8)$ & $101.2(6)$ \\
\hline$S(1)-C(1)-S(2)$ & $114.7(5)$ & $S(1)-C(1)-C(2)$ & $122.4(7)$ \\
\hline$S(2)-C(1)-C(2)$ & $122.9(7)$ & $S(3)-C(2)-S(4)$ & $114.5(5)$ \\
\hline$S(3)-C(2)-C(1)$ & $121.7(7)$ & $S(4)-C(2)-C(1)$ & $123.7(7)$ \\
\hline$S(1)-C(3)-S(5)$ & $115.5(5)$ & $S(1)-C(3)-C(4)$ & $115.0(6)$ \\
\hline$S(5)-C(3)-C(4)$ & $129.5(7)$ & $S(2)-C(4)-S(6)$ & $115.6(5)$ \\
\hline$S(2)-C(4)-C(3)$ & $118.1(6)$ & $S(6)-C(4)-C(3)$ & $126.3(6)$ \\
\hline$S(3)-C(5)-S(7)$ & $115.2(5)$ & $S(3)-C(5)-C(6)$ & $115.8(6)$ \\
\hline$S(7)-C(5)-C(6)$ & $129.0(7)$ & $S(4)-C(6)-S(8)$ & $115.8(5)$ \\
\hline$S(4)-C(6)-C(5)$ & $116.8(6)$ & $S(8)-C(6)-C(5)$ & $127.4(7)$ \\
\hline$S(7)-C(7)-C(8)$ & 124.1(9) & $S(8)-C(8)-C(7)$ & $132.8(9)$ \\
\hline$S(5)-C(9)-C(10)$ & $123.9(8)$ & $S(6)-C(10)-C(9)$ & $125.4(9)$ \\
\hline$C(11)-S(9)-C(12)$ & $96.0(4)$ & $C(11)-S(10)-C(13)$ & $96.5(4)$ \\
\hline$C(12)-S(11)-C(14)$ & $101.8(4)$ & $C(13)-S(12)-C(15)$ & $102.0(4)$ \\
\hline$S(9)-C(11)-S(10)$ & $113.7(4)$ & $S(9)-C(11)-C(11 a)$ & $123.1(10)$ \\
\hline$S(10)-C(11)-C(11 a)$ & $123.2(10)$ & $S(9)-C(12)-S(11)$ & $114.2(5)$ \\
\hline$S(9)-C(12)-C(13)$ & $117.8(6)$ & $S(11)-C(12)-C(13)$ & $128.0(7)$ \\
\hline$S(10)-C(13)-S(12)$ & $115.1(5)$ & $S(10)-C(13)-C(12)$ & $116.0(6)$ \\
\hline$S(12)-C(13)-C(12)$ & $128.9(7)$ & $S(11)-C(14)-C(15)$ & $113.9(5)$ \\
\hline$S(12)-C(15)-C(14)$ & $113.6(6)$ & $O(1)-N(1)-O(2)$ & $121.0(8)$ \\
\hline $\mathrm{O}(1)-\mathrm{N}(1)-\mathrm{O}(3)$ & $122.0(10)$ & $O(2)-N(1)-O(3)$ & $116.9(10)$ \\
\hline
\end{tabular}

Table II. Bond distances $(\AA)$ and angles ( ${ }^{\circ}$.

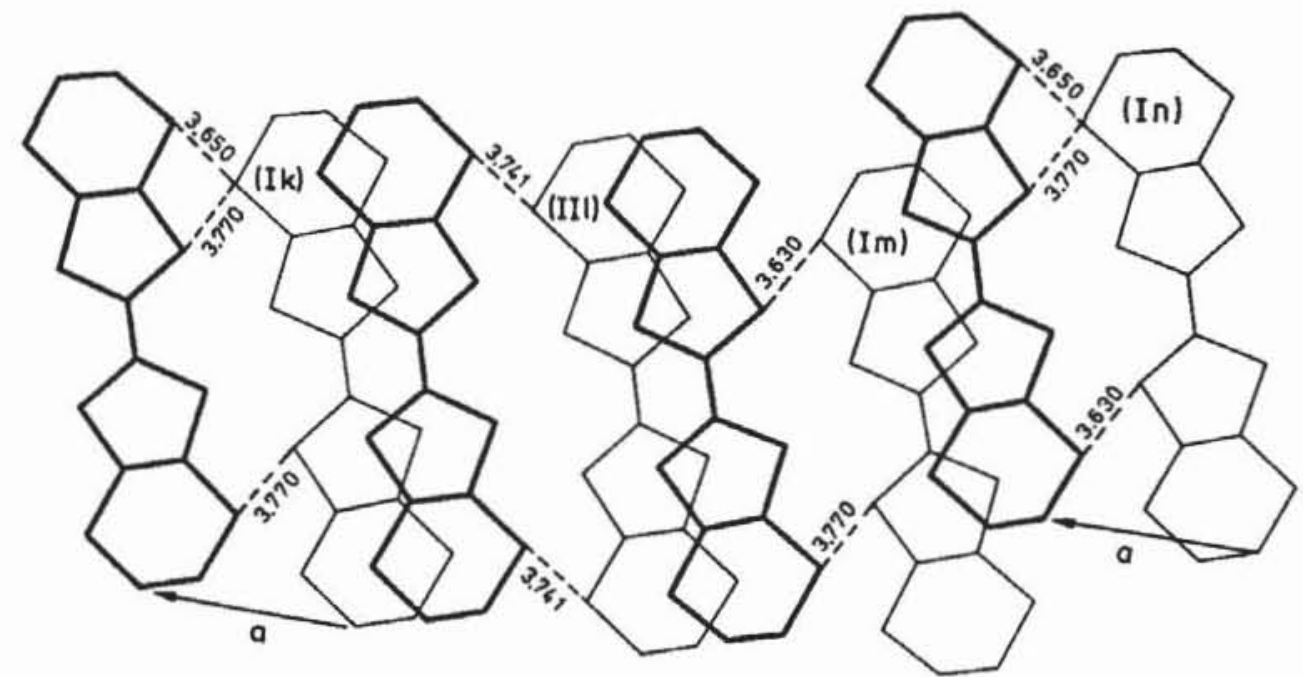

Fig. 3. Two BEDT-TTF ribbons, related by a unit translation $a$, projected onto each other. The projection is perpendicular to the mean plane through the $\mathrm{S}$ atoms of species (I). The lower molecules (thin lines) are the same as in Fig. 2, they are shifted by $a$ (direction shown in the Figure) to give the upper ribbon (thick lines). S $\cdots$ S contacts $<3.8 \AA$ between the different ribbons are indicated. 


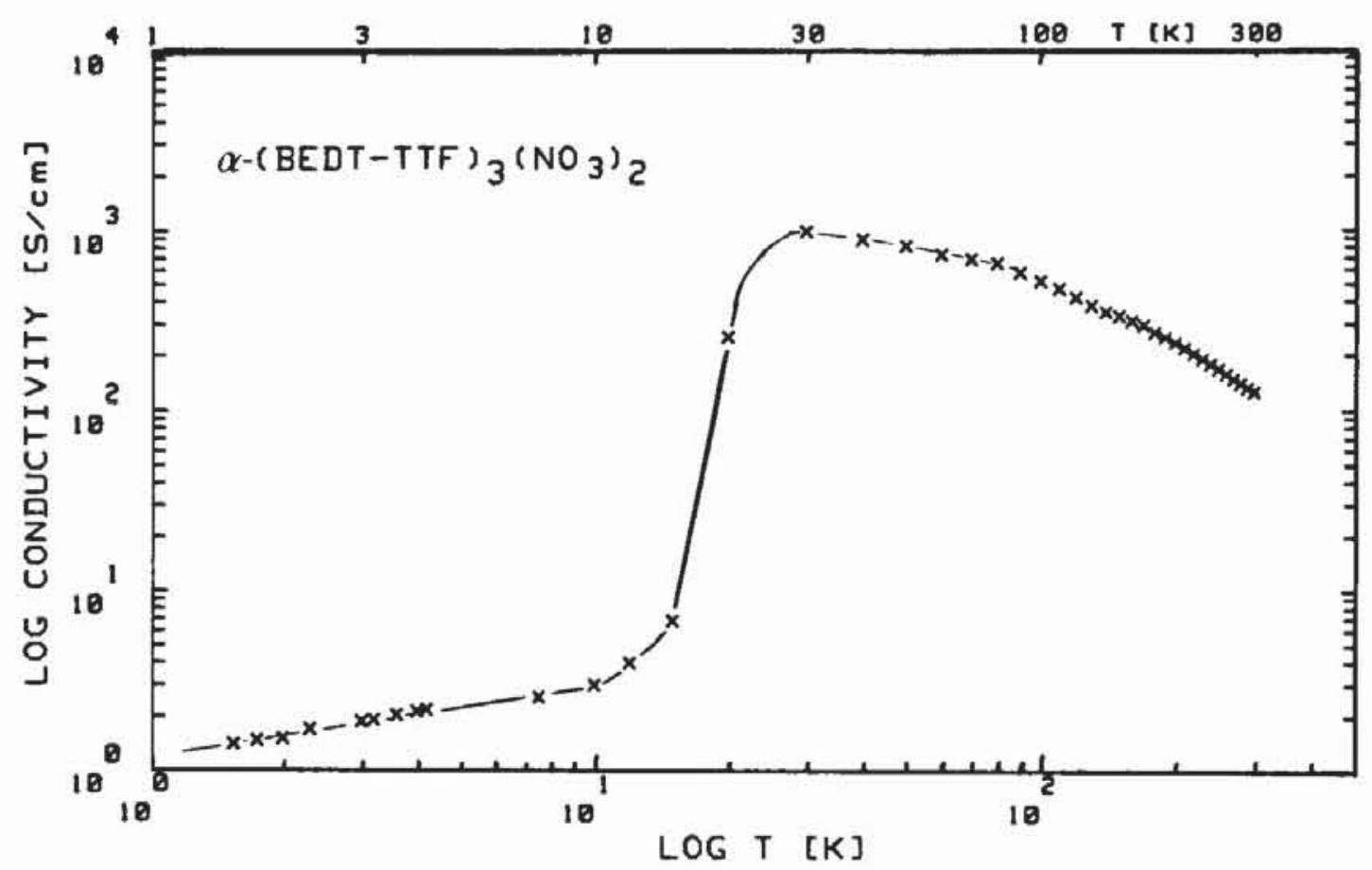

Fig. 4. Temperature dependence of the conductivity of an $\alpha$-(BEDT-TTF $)_{3}\left(\mathrm{NO}_{3}\right)_{2}$ crystal showing a sharp decrease in conductivity around $20 \mathrm{~K}$.

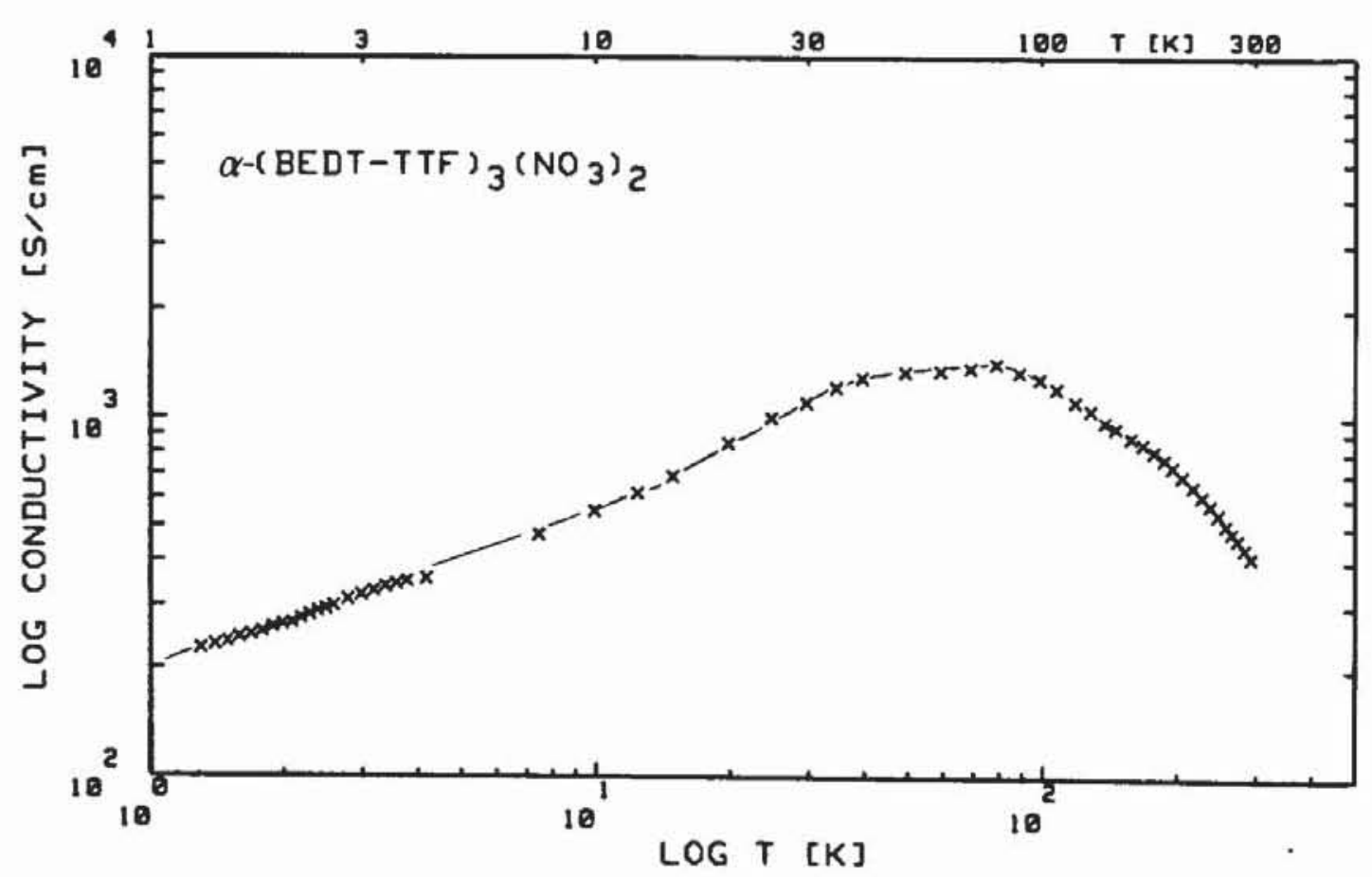

Fig. 5. Temperature dependence of the conductivity of an $\alpha$-(BEDT-TTF $)_{3}\left(\mathrm{NO}_{3}\right)_{2}$ crystal with a smooth decrease in conductivity below $30 \mathrm{~K}$.

conducting behaviour with a very small activation energy of $1.5 \cdot 10^{-4} \mathrm{eV}$.

Crystals with a conductivity characteristic shown in Fig. 5 conduct at $4 \mathrm{~K}$ as well as at room temperature.
All crystals showed also a small dip in the $\log (\mathrm{S} / \mathrm{cm}) / \log \mathrm{T}$-curve at around $140-150 \mathrm{~K}$. In the same temperature range the thermopower measurements (Fig. 6) indicate another phase transition. In 


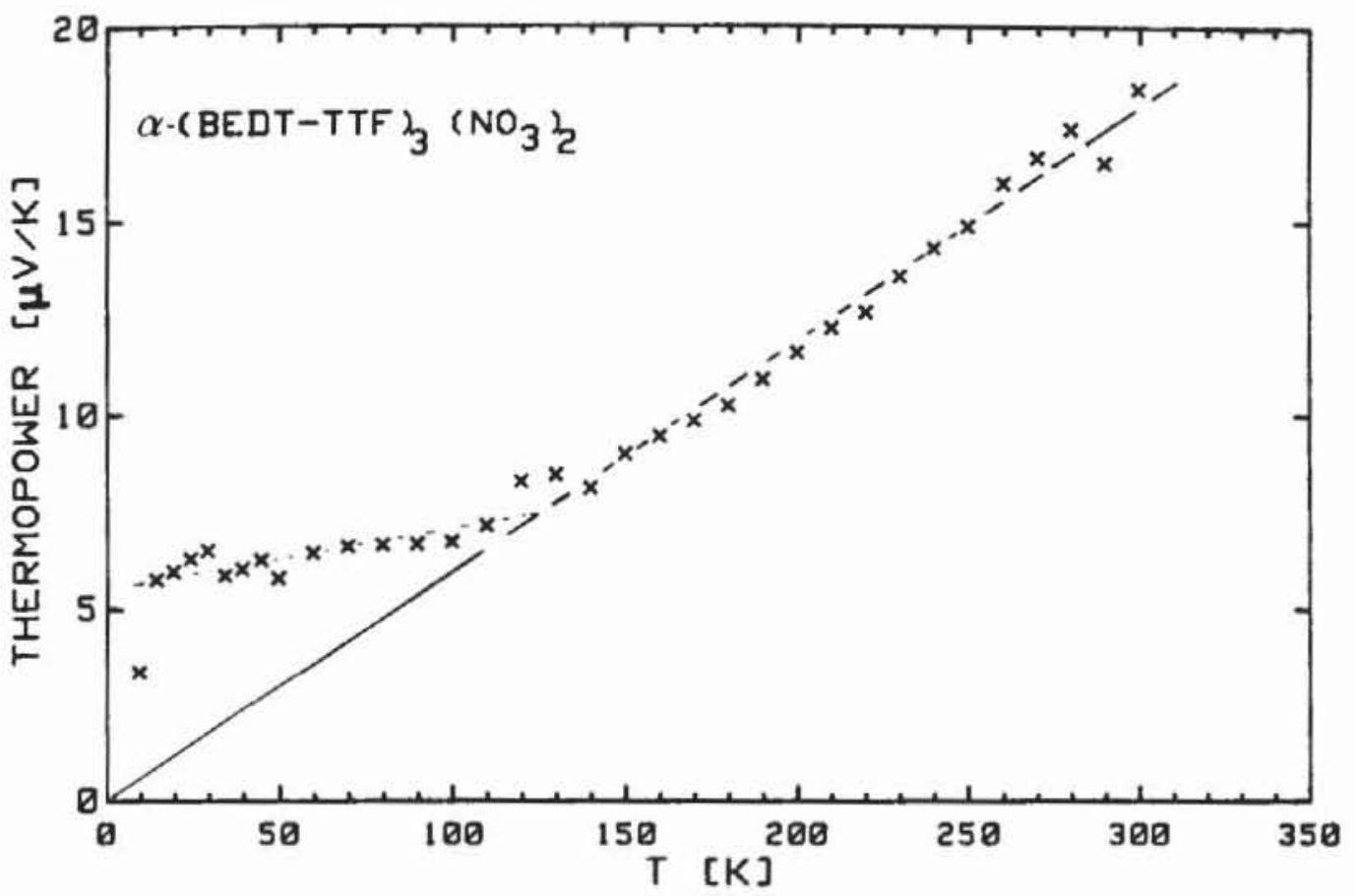

Fig. 6. Temperature dependence of the thermopower of crystals of $\alpha$-(BEDT-TTF $)_{3}\left(\mathrm{NO}_{3}\right)_{2}$ measured along the $a$-direction.

both temperature ranges between $140-300 \mathrm{~K}$ and between $20-140 \mathrm{~K}$ a linear temperature dependent thermopower $\mathbf{S}$ typical for a metallic regime is found. The slopes of the thermopower above and below $140 \mathrm{~K}$ indicate that the width of the conduction band might be much larger in the low temperature regime.
The structure and physical properties of the $\beta$ - and $\gamma$-phases are reported separately [17].

This work was supported by Stiftung Volkswagenwerk and by the Fonds der Chemischen Industrie.
[1] S. S. P. Parkin, E. M. Engler, R. R. Schumaker, R. Lagier, V. Y. Lee, J. C. Scott, and R. L. Greene, Phys. Rev. Lett. 50, 270 (1983).

[2] E. B. Yagubskii, I. F. Shchegolev, V. N. Laukhin, P. A. Kononovich, M. W. Karatsovnik, A. V. Zwarykina, and L. I. Buravou, Pis'ma Zh. Eksp. Teor. Fiz. 39, 12 (1984); J. E. T. P. Lett. 39, 129 (1984).

[3] H. Schwenk, C. P. Heidmann, F. Gross, E. Hess, K. Andres, D. Schweitzer, and H. J. Keller, Phys. Rev. B 31, 3138 (1985).

[4] T. Mori, A. Kobayashi, Y. Sasaki, H. Kobayashi, G. Saito, and H. Inokuchi, Chem. Lett. 1984, 957 (1984).

[5] K. Murata, M. Tokumoto, H. Anzai, H. Bando, G. Saito, K. Kajimura, and T. Ishiguro, J. Phys. Soc. Jpn. 54, 1236 (1985).

[6] J. M. Williams, H. H. Wang, M. A. Beno, T. J. Emge, L. M. Sowa, P. T. Copps, F. Behroozi, L. N. Hall, K. D. Carlson, and G. W. Crabtree, Inorg. Chem. 23, 3839 (1984).

[7] T. J. Emge, H. H. Wang, M. A. Beno, P. C. W. Leung, M. A. Firestone, H. J. Jenkins, J. D. Cook, K. D. Carlson, and J. M. Williams, Inorg. Chem. 24, 1736 (1985).

[8] H. H. Weng, M. A. Beno, U. Geiser, M. A. Firestone, K. S. Webb, L. Nunez, G. W. Crabtree, K. D. Carlson, J. M. Williams, L. J. Azevedo, J. F. Kwak, and J. E. Schirber, Inorg. Chem. 24, 2465 (1985).
[9] H. Endres, M. Hiller, H. J. Keller, K. Bender, E. Gogu, I. Heinen, and D. Schweitzer, Z. Naturforsch. 40 b, 1664 (1985).

[10] M. Mizumo, A. F. Garito, and M. P. Cava, J. Chem. Soc. Chem. Commun. 1978, 18.

[11] K. Hartke, T. Kissel, J. Quante, and R. Matusch, Chem. Ber. 113, 1898 (1980).

[12] H. J. Keller, D. Nöthe, H. Pritzkow, D. Wehe, M. Werner, P. Koch, and D. Schweitzer, Mol. Cryst. Liq. Cryst. 62, 181 (1980).

[13] K. Bender, I. Hennig, D. Schweitzer, K. Dietz, H. Endres, and H. J. Keller, Mol. Cryst. Liq. Cryst. 108, 359 (1984).

[14] P. M. Chaikin and J. F. Kwan, Rev. Sci. Instrum. 46, 218 (1975).

[15] G. M. Sheldrick, SHELXTL. An integrated system for solving, refining, and displaying crystal structures from diffraction data. Univ. Göttingen, FRG (1983).

[16] International Tables for X-ray Crystallography. Vol. IV. Kynoch Press, Birmingham 1974 (Present distributor: D. Reidel, Dordrecht).

[17] E. Gogu, I. Heinen, K. Bender, D. Schweitzer, A. Weber, H. Endres, and H. J. Keller, Mol. Cryst. Liq. Cryst., to be submitted. 